\title{
Expression of Kv1.1, a Shaker-Like Potassium Channel, Is Temporally Regulated in Embryonic Neurons and Glia
}

\author{
Janice L. Hallows and Bruce L. Tempel \\ The Virginia Merrill Bloedel Hearing Research Center and the Departments of Pharmacology and Otolaryngology-Head \\ and Neck Surgery, University of Washington School of Medicine, Seattle, Washington 98195
}

Kv1.1, a Shaker-like voltage-gated potassium channel, is strongly expressed in a variety of neurons in adult rodents, in which it appears to be involved in regulating neuronal excitability. Here we show that Kv1.1 is also expressed during embryonic development in the mouse, exhibiting two transient peaks of expression around embryonic day 9.5 (E9.5) and E14.5. Using both in situ hybridization and immunocytochemistry, we have identified several cell types and tissues that express Kv1.1 RNA and protein. At E9.5, Kv1.1 RNA and protein are detected transiently in non-neuronal cells in several regions of the early CNS, including rhombomeres 3 and 5 and ventricular zones in the mesencephalon and diencephalon. At E14.5, several cell types in both the CNS and peripheral nervous system express
Kv1.1, including neuronal cells (sensory ganglia and outer aspect of cerebral hemispheres) and glial cells (radial glia, satellite cells, and Schwann cell precursors). These data show that Kv1.1 is expressed transiently in a variety of neuronal and non-neuronal cells during restricted periods of embryonic development. Although the functional roles of Kv1.1 in development are not understood, the cell-specific localization and timing of expression suggest this channel may play a role in several developmental processes, including proliferation, migration, or cell-cell adhesion.

Key words: voltage-gated potassium channel; embryo; development; mouse; Kv1.1; glia; neuron; rhombomere; expression
Voltage-gated potassium $(\mathrm{Kv})$ channels are a diverse group of ion-selective channels found in the membranes of excitable cells. Their physiological functions in mature neurons include determination of resting membrane potentials, shaping of action potentials, regulation of neuronal firing patterns, and modulation of neurotransmitter release. In addition to these roles in neurons, $\mathrm{Kv}$ channels play a transport role in epithelial and glial cells (for review, see Hille, 1992). In contrast to their relatively well studied roles in mature organisms, the cellular expression patterns and functional roles played by $\mathrm{Kv}$ channels in embryogenesis are less well defined.

Several potassium $\left(\mathrm{K}^{+}\right)$currents are developmentally regulated in nonmammalian species, including those identified in oocytes (Hagiwara et al., 1975; Moody, 1985), during early cleavages (deLatt and Bluemink, 1974), around the time of gastrulation (Simoncini et al., 1988), and during muscle differentiation (Ribera and Spitzer, 1991; Spruce and Moody, 1992). One of the most extensively studied $\mathrm{K}^{+}$currents in nonmammalian embryos is a delayed rectifier $\mathrm{K}^{+}$current $\left(I_{\mathrm{Kv}}\right)$ that is first detected during neurogenesis in amphibians. Differentiation of this current is essential for normal neuronal development; the appearance of $I_{\mathrm{Kv}}$

Received Feb. 11, 1998; revised April 17, 1998; accepted May 12, 1998.

This work was supported by National Institutes of Health Grants NS27206 (B.L.T.) and GM07750 (J.L.H.). We thank Dr. Pate Skene (Duke University) for the gift of anti-GAP-43 antibodies, Dr. A. Frankfurter (University of Virginia) for the gift of TuJ1 antibodies, and Drs. M. Bosma, D. Frost, C. Olsson, and E. Rubel for their critical comments on this manuscript. The monoclonal antibodies 40E-C and RC-2 were obtained from the Developmental Studies Hybridoma Bank maintained by the Department of Pharmacology and Molecular Sciences, Johns Hopkins University School of Medicine (Baltimore, MD) and the Department of Biological Sciences, University of Iowa (Iowa City, IA) under contract N01-HD-6-2915 from the National Institute of Child Health and Human Development.

Correspondence should be addressed to Dr. Bruce L Tempel, The Virginia Merrill Bloedel Hearing Research Center, Box 357923, University of Washington School of Medicine, Seattle, WA 98195.

Copyright (C) 1998 Society for Neuroscience $\quad 0270-6474 / 98 / 185682-10 \$ 05.00 / 0$ is crucial for the transition from early, long-duration action potentials to mature, brief spikes (Barish, 1986; O'Dowd et al., 1988; Lockery and Spitzer, 1992). Several lines of evidence suggest that the expression of Xenopus Kv1.1 (xKv1.1) may play an important part in the development of $I_{\mathrm{Kv}}$ and thus in neuronal development. First, developing Xenopus spinal neurons express xKv1.1 and $\mathrm{xKv} 2.2$, which are homologous in sequence and expressed currents to previously identified mammalian Kv channels, Kv1.1 and Kv2.2, respectively (Ribera and Nguyen, 1993; Burger and Ribera, 1996). The spinal neurons are homogenous with respect to development of $I_{\mathrm{Kv}}$ (O'Dowd et al., 1988; Desarmenien et al., 1993), but different $\mathrm{Kv}$ channels underlie $I_{\mathrm{Kv}}$ in different neurons. Overexpression of a dominant-negative Kv1 subunit suggests that $20 \%$ of spinal neurons express only Kv1 potassium currents (Ribera, 1996). Second, early overexpression of xKv1.1 in cultured spinal neurons results in the premature appearance of $I_{\mathrm{Kv}}$ and a reduction in the number of morphologically differentiated neurons (Jones and Ribera, 1994). Third, both xKv1.1 and xKv2.2 transcripts are temporally regulated in developing spinal neurons during the period of $I_{\mathrm{Kv}}$ development (Gurantz et al., 1996).

The development of $I_{\mathrm{Kv}}$ has been less well studied in mammals, although limited data suggest this current is essential for mammalian neuronal development as well. Delayed rectifier currents have been identified in several types of rodent embryonic cultured neurons, including rat cortical (Zona et al., 1990; Rizzo and Nonner, 1992) and neostriatal (Surmeier et al., 1991) neurons, mouse hippocampal neurons (Wu and Barish, 1994), and rat and mouse spinal cord and dorsal root ganglia (DRG) neurons (Naciff et al., 1996); however, the molecular identity of the channel subunit types that contribute to these currents is unknown. Moreover, it is not known what other cells express delayed rectifier channels during murine development or whether their expression is temporally regulated. We show here that Kv1.1 is expressed in 
a complex temporal and tissue-specific pattern during murine development. Implications for possible developmental functions of Kv channels are discussed.

\section{MATERIALS AND METHODS}

Animals. $\mathrm{C}_{3} \mathrm{HeB} / \mathrm{FeJ}$ mice obtained from Jackson Laboratories were maintained in our colony on a $12 \mathrm{hr}$ light/dark cycle. Breeding pairs were established, and females were examined each morning for the presence of a vaginal plug. We designated 12:00 P.M. (noon) on the day a plug was detected embryonic day 0.5 (E0.5), and dissections were begun at approximately noon at indicated ages. Embryos were quickly dissected in PBS (137 mM NaCl, $2.7 \mathrm{~mm} \mathrm{KCl,} 10 \mathrm{~mm} \mathrm{Na} \mathrm{HPO}_{4}$, and $1.75 \mathrm{~mm}$ $\mathrm{KH}_{2} \mathrm{PO}_{4}$ ) and were homogenized in guanidinium buffer (4 M guanidinium thiocyanate, $24 \mathrm{~mm}$ sodium citrate, $17 \mathrm{~mm} N$-lauroylsarcosine, and $7 \% \beta$-mercaptoethanol) for RNA isolation, quickly frozen on dry ice for in situ hybridization, or fixed for $2 \mathrm{hr}$ in $4 \%$ paraformaldehyde in PBS for immunocytochemistry. Whole brains from postnatal mice were quickly dissected in PBS and homogenized in guanidinium for RNA isolation.

RNA and RNase protection. The guanidinium thiocyanate method (Chomczynski and Sacchi, 1987) was used to isolate total RNA from whole brains and whole embryos at E13.5-E16.5 or from pooled embryos at E8.5-E12.5. RNA concentration was determined by spectrophotometric measurement, and $0.5-1 \mu \mathrm{g}$ of total RNA was electrophoresed on a $1 \%$ agarose $/ 18 \%$ formaldehyde gel to verify that the RNA was intact.

A region of Kv1.1 that spans the translational start site was used as a template to generate a 310 base pair (bp) $5^{\prime}$-antisense riboprobe that yields a $252 \mathrm{bp}$ ( $42 \mathrm{bp} 5^{\prime}$-untranslated region and $210 \mathrm{bp}$ open-reading frame) protected fragment (Bosma et al., 1993) when digested with RNases A and T1 (Ausubel, 1992). We mixed 20-25 $\mu \mathrm{g}$ of total RNA with $10^{5} \mathrm{cpm}$ of probe, and before hybridization, aliquots of samples were diluted $10^{-5}$ and hybridized to a 423 bp probe that protects a 350 bp fragment of $18 \mathrm{~S}$ ribosomal RNA to monitor the amount of total RNA in samples. Gels were apposed to Hyperfilm MP (Amersham, Arlington Heights, IL) for $4-5 \mathrm{~d}$ at $-80^{\circ} \mathrm{C}$ to generate autoradiographs and then were subjected to PhosphorImager (Molecular Dynamics, Sunnyvale, CA) analysis, and the density of protected fragments was quantitated at the Fred Hutchinson Cancer Research Center.

In situ hybridization. Frozen embryos were cut into $20 \mu \mathrm{m}$ sagittal sections on a cryostat, mounted on 3-aminopropyltriethoxysilane-treated slides, processed, hybridized to ${ }^{33} \mathrm{P}$-labeled sense and antisense $5^{\prime}$-probes (see above), and washed as previously described (Wang et al., 1994). Experiments were also performed using a $3^{\prime}$-probe that spans the $\mathrm{C}$ terminal (41 bp of open-reading frame and $207 \mathrm{bp}$ of $3^{\prime}$-untranslated region).

Slides were apposed to Hyperfilm $\beta$-max (Amersham) for $5-6 \mathrm{~d}$ to generate autoradiographs and then were coated with Kodak NBT-2 emulsion, stored at $4^{\circ} \mathrm{C}$ for $10-12 \mathrm{~d}$, developed, and counterstained with hematoxylin.

Autoradiographic film images were enlarged and digitized using a Dage CCD 72 camera, a Macintosh IIci computer, and the public domain program National Institutes of Health Image. Final images were generated using a Power Macintosh 8500 and Deneba Canvas software. Darkfield images of emulsion-coated slides were collected using National Institutes of Health Image, a Nikon Optiphot microscope, and a Sony CCD-IRIS video camera, and final images were generated using Adobe Photoshop and Deneba Canvas software. Digital images were printed using the Tektronix Phaser II SD dye sublimation system.

Immunocytochemistry. Fixed embryos were cryoprotected in sucrose, frozen in embedding medium, cut in $10-20 \mu \mathrm{m}$ sagittal sections on a cryostat, and affixed to chrome alum-treated slides. Immunocytochemistry (ICC) was performed according to Wang (Wang et al., 1993), and sections were incubated with the following primary antibodies for $3 \mathrm{~d}$ at $4^{\circ} \mathrm{C}$ : polyclonal anti-Kv1.1 at 1:25 (Wang et al., 1993); monoclonal TuJ1 antibody against neuron-specific class III $\beta$-tubulin at 1:500 (Moody et al., 1989; Easter et al., 1993); monoclonal 40E-C antibody against vimentin at 1:25 (Alvarez-Buylla et al., 1987); monoclonal RC-2 antibody specific for radial glia at 1:1 (Misson et al., 1988); polyclonal anti-Krox-20 at 1:50 (Goddard et al., 1996) (Berkeley Antibody Co.); and monoclonal anti-GAP-43 at 1:2000 (Goslin et al., 1990). Double staining with antiKv1.1 in combination with monoclonal antibodies (TuJ1, 40E-C, RC-2, and GAP-43) was performed by coincubation with both primary antibodies. Double staining with anti-Kv1.1 and anti-Krox-20 (both polyclonal) antibodies was performed using sequential incubations, separated by a blocking step using goat anti-rabbit $\operatorname{IgG~F}\left(\mathrm{ab}^{\prime}\right)_{2}$ fragments (Jackson ImmunoResearch, West Grove, PA) at $6 \mathrm{ng} / \mu \mathrm{l}$. Incubation with fluorescent secondary antibodies was simultaneous or sequential as described above and used fluorescein- or Texas Red-conjugated goat anti-rabbit $\mathrm{IgG}$ for polyclonal primary antibodies or goat anti-mouse IgG and IgM for monoclonal primary antibodies (Jackson ImmunoResearch) at $7.5 \mathrm{ng} / \mu \mathrm{l}$.

Images were collected on a Bio-Rad MRC 1024 scanning laser confocal microscope (V. M. Bloedel Center), processed using Adobe Photoshop and Deneba Canvas software, and printed using the Tektronix Phaser II SD dye sublimation system.

\section{RESULTS}

\section{Kv1.1 transcript levels are temporally regulated during murine development}

To determine whether Kv1.1 is expressed during murine embryonic development and whether its expression is developmentally regulated in mice, we performed RNase protection assays, comparing Kv1.1 RNA levels in whole embryos from E9.5 to E16.5. Three separate experiments were performed, using independently isolated tissue samples to generate three different RNA preparations at each embryonic day. The level of Kv1.1 RNA relative to that of $18 \mathrm{~S}$ ribosomal RNA in each sample was calculated by PhosphorImager quantitation of protected fragments. Kv1.1 transcript levels were relatively high at E9.5 and E14.5, with lower expression at interim stages (Fig. $1 A, B$ ). Kv1.1 RNA levels were only slightly lower at E8.5 than at E9.5 $(n=3$; data not shown).

To determine whether Kv1.1 expression is also regulated during postnatal development, we performed similar RNase protection assays comparing transcript levels in whole brain at regular intervals from E17.5 to postnatal day 21 (P21). Three independent experiments detected the lowest Kv1.1 expression at approximately the time of birth, with gradually increasing levels over $\sim 2$ weeks and a dramatic upregulation of expression at $\sim 2$ weeks of age (Fig. $1 C, D)$.

These results demonstrate that Kv1.1 RNA is expressed during murine embryonic development and that RNA levels are regulated in a complex temporal pattern. There are two major peaks of expression during embryonic development, followed by an abrupt increase during the second postnatal week that is sustained throughout adult life.

\section{Kv1.1 RNA decreases from E9.5 to E10.5}

To examine the tissue-specific changes in Kv1.1 transcript levels between E9.5 and E10.5, we performed in situ hybridization studies using sagittally sectioned embryos. Two separate experiments using 5-10 embryos at each age were performed. At E9.5, the Kv1.1 signal was strong in regions of the diencephalon (thalamus and hypothalamus), in the tectum of the mesencephalon (and tegmentum) (data not shown), and in two broad dorsal stripes in the region of the rhombomeres (Fig. 2A,B). By E10.5, we no longer detected Kv1.1 signal in the rhombencephalon, and signal density was significantly lower in the mesencephalon (Fig. $2 C, D)$. Similar results were obtained with both $5^{\prime}$ - and $3^{\prime}$ riboprobes. These data indicate that Kv1.1 expression at E9.5 is transient, confirming the dramatic decrease in Kv1.1 transcript levels from E9.5 to E10.5 that was detected by RNase protection.

\section{Cellular localization of Kv1.1 at E9.5 and E10.5}

Fluorescent ICC experiments using polyclonal antibodies specific to Kv1.1 confirmed the expression pattern observed by in situ hybridization. A minimum of two experiments using 5-10 embryos at each age were performed. Strong Kv1.1 immunoreactiv- 


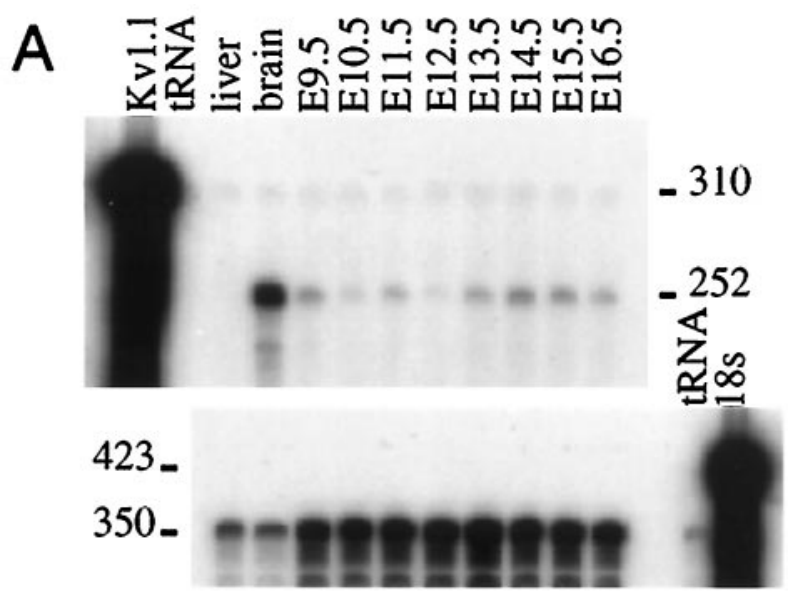

\section{B}
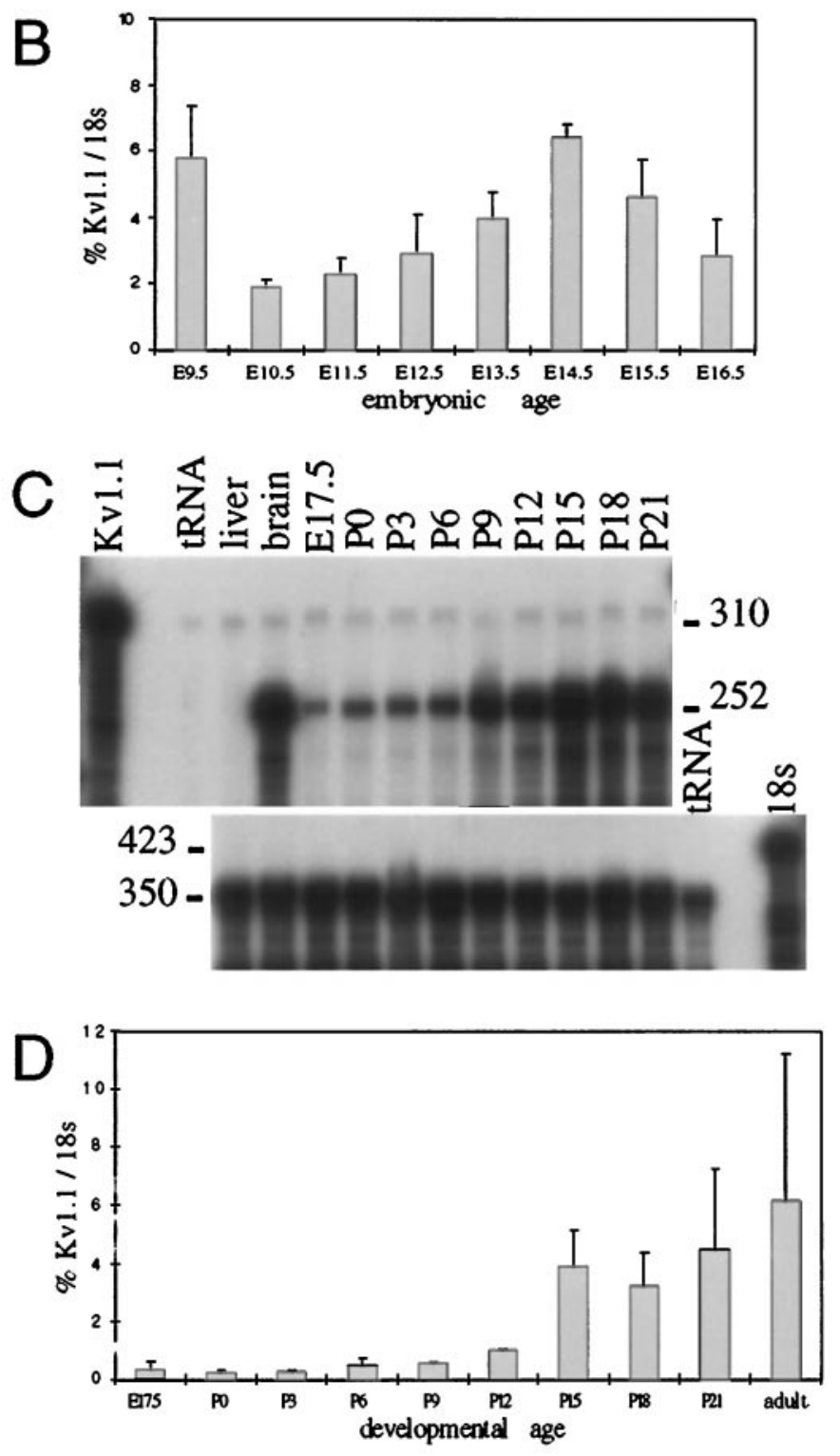

Figure 1. Temporal regulation of Kv1.1 expression. A, Autoradiograph of an RNase protection assay (RPA) gel demonstrating changing Kv1.1 transcript levels from E9.5 to E16.5. Top, Total RNA from adult tissue (liver and brain) or from whole embryos was hybridized to a $310 \mathrm{bp}$ ${ }^{32} \mathrm{P}$-labeled 5'-Kv1.1 antisense riboprobe. After hybridization, RNase ity was detected in two rhombomeres (Fig. $3 A$ ) as well as in the mesencephalon (Fig. $3 F, G$ ). By E10.5, no Kv1.1 immunoreactivity was detected in the rhombomeres (Fig. $3 B$ ), and staining was substantially lower in regions of the diencephalon and mesencephalon that exhibited staining at E9.5 (data not shown).

To identify the cell types expressing Kv1.1 at E9.5 and throughout embryonic development, we performed double-label ICC for Kv1.1 and specific cellular markers. Although the expression of markers used throughout this study is developmentally regulated, each was used at a period in development when its expression has been characterized previously and shown to be localized to the specific cell types identified in this study. Thus, to identify the specific rhombomeres expressing Kv1.1, sections were double labeled with anti-Kv1.1 and antibodies to Krox-20, a zinc-finger transcription factor that localizes to rhombomeres 3 and 5 at E9.5 (Wilkinson et al., 1989). Colabeling identified the two regions of Kv1.1 expression in the hindbrain as rhombomeres 3 and 5 (Fig. $3 C)$. The subcellular localizations of Kv1.1 and Krox-20 within the rhombomeres were not identical (Fig. 3D), as would be expected because Krox-20 is a transcription factor and thus might reasonably be found in the nucleus, whereas Kv1.1 appears cytoplasmic or associated with the plasma membrane.

To address the question of whether Kv1.1 staining at E9.5 is in neurons, sections were double stained with antibodies to Kv1.1 and $\mathrm{TuJ} 1$, a neuron-specific class III $\beta$-tubulin, as a marker of early neuronal development (Moody et al., 1989; Easter et al., 1993). In the hindbrain, the two proteins were found in alternating compartments, and only cells positive for TuJ1 had distinct neuronal morphologies (Fig. $3 E$ ). Kv1.1 and $\mathrm{TuJ} 1$ proteins also failed to colocalize in the E9.5 mesencephalon (Fig. $3 F$ ), where Kv1.1 staining was strongest in the ventricular, or proliferating zone, whereas $\mathrm{TuJ} 1 \mathrm{immunoreactivity} \mathrm{was} \mathrm{observed} \mathrm{mainly} \mathrm{in} \mathrm{the}$ differentiating field. In the ventricular zone, Kv1.1 staining was robust in large branched cells with endfeet at the edge of the ventricle (Fig. $3 F$ ). Double labeling with anti-Kv1.1 and -RC-2, a marker specific for radial glia (Misson et al., 1988), detected both proteins in these branched cells in the ventricular zone (Fig. 3G). Location, morphology, and RC-2 immunoreactivity indicate these cells are radial glia. Collectively, these data indicate that at E9.5, Kv1.1 is not found in cells that are differentiated neurons but is found in a population of early glial cells.

\section{Kv1.1 RNA peaks transiently around E14.5}

In situ hybridization experiments using sectioned embryos were performed to examine the tissue-specific expression of Kv1.1 between E14.5 and E17.5. At E14.5, Kv1.1 transcripts were wide-

$$
\leftarrow
$$

digestion produced a 252 bp protected fragment. Bottom, Samples were diluted and hybridized to a 423 bp ${ }^{32} \mathrm{P}$-labeled $18 \mathrm{~S}$ ribosomal subunit riboprobe (350 bp protected fragment) to control for the amount of RNA in each sample. Fragment sizes are indicated in base pairs. $B$, PhosphorImager (PI) analysis of three RPA gels using three different sets of RNA preparations. Kv1.1 band intensity is expressed as a percentage of the corresponding $18 \mathrm{~S}$ band intensity and is plotted on the $y$-axis versus embryonic age on the $x$-axis. Relatively high expression of Kv1.1 is detected at E9.5 and E14.5, separated by a period of lower expression. Error bars indicate SE. $C$, Autoradiograph of an RPA gel demonstrating changing Kv1.1 RNA levels in the CNS from E17.5 to P21. Total RNA from whole brains was hybridized to the same probes described in $A . D$, PI analysis of three RPA gels demonstrating that Kv1.1 RNA levels in whole brain are lowest at approximately the time of birth and are dramatically upregulated at $\sim 2$ weeks of age. Error bars indicate SE. 


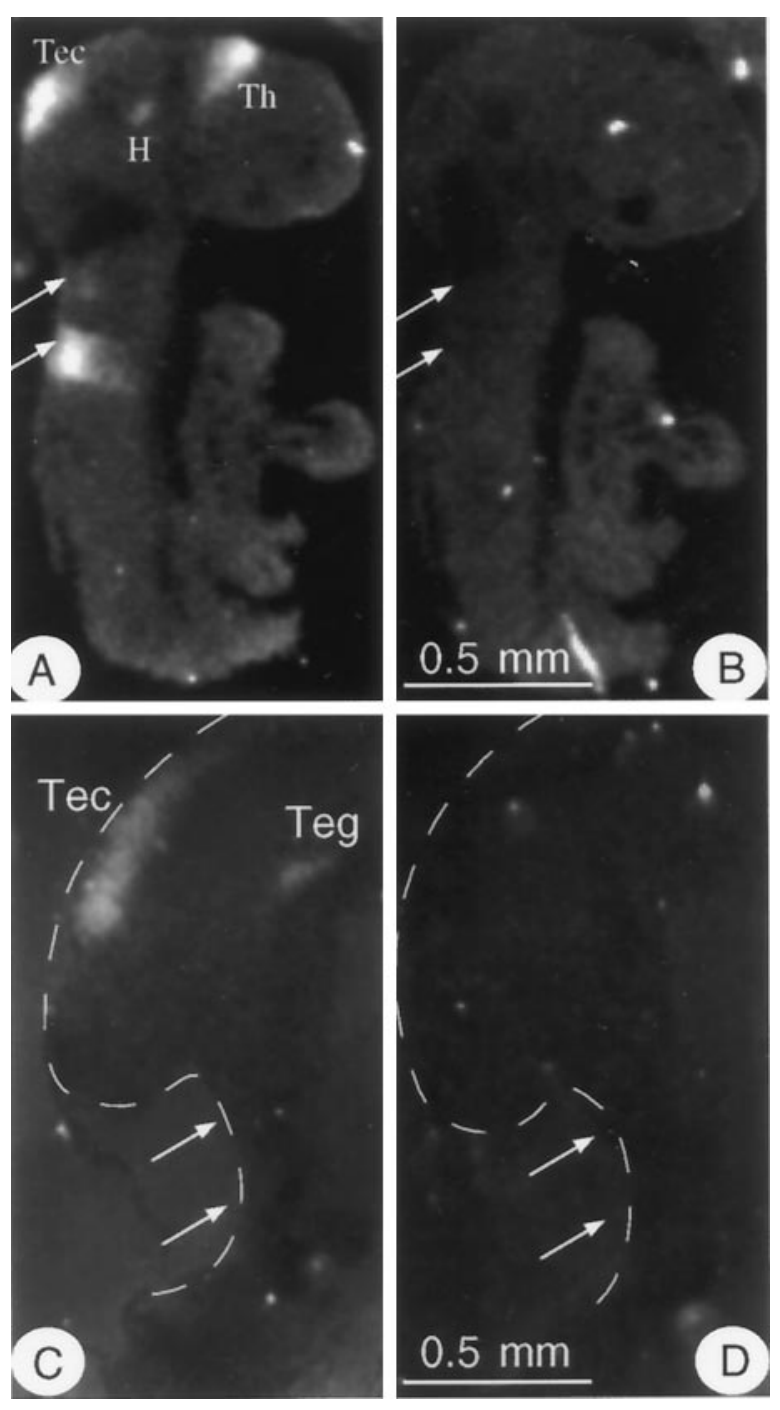

Figure 2. Tissue-specific expression of Kv1.1 RNA between E9.5 and E10.5. Note that embryos nearly double in size during this $24 \mathrm{hr}$ period; thus only a fraction of an E10.5 embryo is visible in the same size field that shows an entire embryo at E9.5. $A, B$, Dark-field images generated by in situ hybridization of adjacent E9.5 sagittal sections with ${ }^{33} \mathrm{P}$-labeled $5^{\prime}$-Kv1.1 antisense, or hybridizing $(A)$, and sense, or control $(B)$, riboprobes. Strong Kv1.1 expression is found in the diencephalon [thalamus $(T h)$ and hypothalamus $(H)$ ], in the mesencephalon [tectum $(T e c)]$, and in two broad dorsal stripes in the hindbrain (arrows). $C, D$, Dark-field images of E10.5 sagittal sections hybridized with the same antisense $(C)$ and sense $(D)$ probes described above. The tissue edge is marked with a dashed line. Signal density is significantly diminished in the mesencephalon [Tec and tegmentum (Teg)], and no Kv1.1 RNA is detected in the hindbrain (arrows).

spread in both the developing CNS and peripheral nervous systems (PNS), with particularly strong expression in sensory structures (Fig. 4A, $B$, Table 1). By E17.5, Kv1.1 signal was significantly lower in the CNS but still relatively high in sensory ganglia (Fig. $4 C, D$, Table 1). These experiments confirm the decrease in Kv1.1 expression from E14.5 to E17.5 that was detected by RNase protection and demonstrate that, in some CNS structures, there is a second period of transient Kv1.1 expression during mouse development. Interestingly, Kv1.1 RNA was detected along the pathways of several peripheral nerves at both E14.5 and E17.5, suggesting its presence in either glia or axons.

\section{Cellular localization of Kv1.1 at E14.5 and E15.5}

Because Kv1.1 expression is so widespread at E14.5, we have focused our tissue-specific examination of expression on three regions of the nervous system: (1) cortex and hippocampus, (2) DRG and peripheral nerves, and (3) trigeminal ganglion and nerve. Each of these regions gives rise to both neurons and glia, but each has a different embryonic origin; the cortex and hippocampus are derived primarily from neural ectoderm, the DRG is from primarily neural crest cells, and the trigeminal ganglion is from both neural crest and placodal cells (for review, see Jacobson, 1991). Despite having different embryonic origins, the results for each region are similar, namely, that Kv1.1 appears in a subset of neurons as well as in a subset of non-neuronal cells. In most cases, these non-neuronal cells were identified as glia, based on location, morphology, and staining with antibodies to either vimentin, RC-2, or Krox-20.

\section{Cortex and hippocampus}

At E14.5, Kv1.1 RNA hybridization signal was strong in the cortex and hippocampus, appearing predominantly in the outer aspects or differentiating fields (Fig. $5 A$ ). Kv1.1 protein was also detected in the cortical and hippocampal differentiating fields, and immunostaining was very robust in large individual cells within the subventricular zone (Fig. $5 B, C$ ). Double-staining ICC experiments demonstrated some overlap in Kv1.1 and TuJ1 immunoreactivities in the differentiating fields (Fig. 5D), whereas the cells in the subventricular zone exhibited either Kv1.1 or TuJ1 staining but not both (Fig. $5 E$ ). In some instances, TuJ1-positive cells were located immediately adjacent to cells with Kv1.1 immunoreactivity, suggesting that the Kv1.1-positive cells in the subventricular zone were radial glia. ICC experiments were performed using two glial markers: vimentin, which is expressed in radial glia and glial precursors (Alvarez-Buylla et al., 1987), and RC-2, a marker specific for radial glia (Misson et al., 1988). Both vimentin (Fig. $5 F$ ) and RC-2 (Fig. $5 G$ ) immunoreactivities were found in cells with Kv1.1 protein, indicating that Kv1.1 is expressed in radial glia and possibly glial precursors. Interestingly, Kv1.1 was found only in a subset of cells positive for RC-2. These data indicate that in the E14.5 cortex and hippocampus, Kv1.1 is expressed in a subset of both neurons and glia.

\section{$D R G$ and peripheral nerves}

At E14.5, Kv1.1 RNA expression was robust in a subset of cells in the DRG (Fig. 6A) and was also detected along the pathways of peripheral nerves (Fig. 4A). ICC experiments confirmed the expression of Kv1.1 protein in only a subset of ganglion neuron somata and also revealed a population of small, rounded cells adjacent to sensory ganglia and along peripheral nerves with very robust Kv1.1 immunoreactivity (Fig. 6B). Colabeling studies using anti-Kv1.1 and either of two early neuronal markers, TuJ1 (Moody et al., 1989; Easter et al., 1993) or GAP-43 (Goslin et al., 1990), showed that Kv1.1 is expressed in neurons with at least two sizes of cell bodies and that the adjacent Kv1.1-expressing cells are not neuronal somata or axons (Fig. $6 C, D$ ). Because sensory ganglion neurons are sometimes classified based on differences in somata size (for review, see Kai, 1989; Carr and Nagy, 1993), the presence of Kv1.1 protein in multiple sizes of neurons suggests this channel may be expressed in multiple neuronal populations within the ganglia.

Krox-20, which is not specific for glial cells but is found in 
Figure 3. Cellular localization of Kv1.1 protein at E9.5 and E10.5 using sagittal sections. The orientations are the same for $A-E$, with dorsal $(D)$ to the left and ventral $(V)$ to the right as shown in $A$. $A$, Fluorescent ICC at E9.5 using polyclonal antibodies specific for Kv1.1 and Texas Red-conjugated secondary antibodies detects strong Kv1.1 immunostaining in two regions of the hindbrain. $B$, A similar experiment at E10.5 does not detect any Kv1.1 protein in the hindbrain. $C$, Double staining ICC at E9.5 with anti-Kv1.1 (red, shown alone in upper right box) and anti-Krox-20 (green, shown alone in lower box) demonstrates colocalization of both proteins in rhombomeres 3 (r3) and r5. The tissue in $C$ and $D$ was exposed to detergent twice as long as tissue in other panels (two sequential polyclonal antibodies), resulting in decreased membrane integrity and a more diffuse staining pattern with higher background. $D$, Approximately sixfold magnification of the boxed area on the lower left in $C$ shows Krox-20 immunoreactivity ( green, shown alone in lower right box) surrounded by Kv1.1 staining (red, shown alone in upper right box). E, Colabeling with anti-Kv1.1 (red) and the early neuronal marker TuJ1 (green) demonstrates that the two proteins are found in alternating rhombomeres, with Kv1.1 in oddnumbered ( 3 and 5) and TuJ1 in evennumbered rhombomeres. Because embryos were staged by vaginal plug date and not somite number, the animals used in $A$ and $E$ are probably at slightly different developmental ages, and the difference in Kv1.1 staining may represent a rostral-caudal gradient that is often observed for molecules with rhombomere-restricted expression. $F$, Double ICC at E9.5 shows nonoverlapping Kv1.1 (red) and TuJ1 (green) immunoreactivities in the thalamus. Kv1.1 immunoreactivity is robust in large cells with endfeet at the edge of the ventricle (arrows). The ventricle $(V)$ is to the left. $G$, Colabeling with anti-Kv1.1 (green) and -RC-2 (red) demonstrates colocalization of both proteins in branched cells with endfeet at the ventricular edge (arrows).
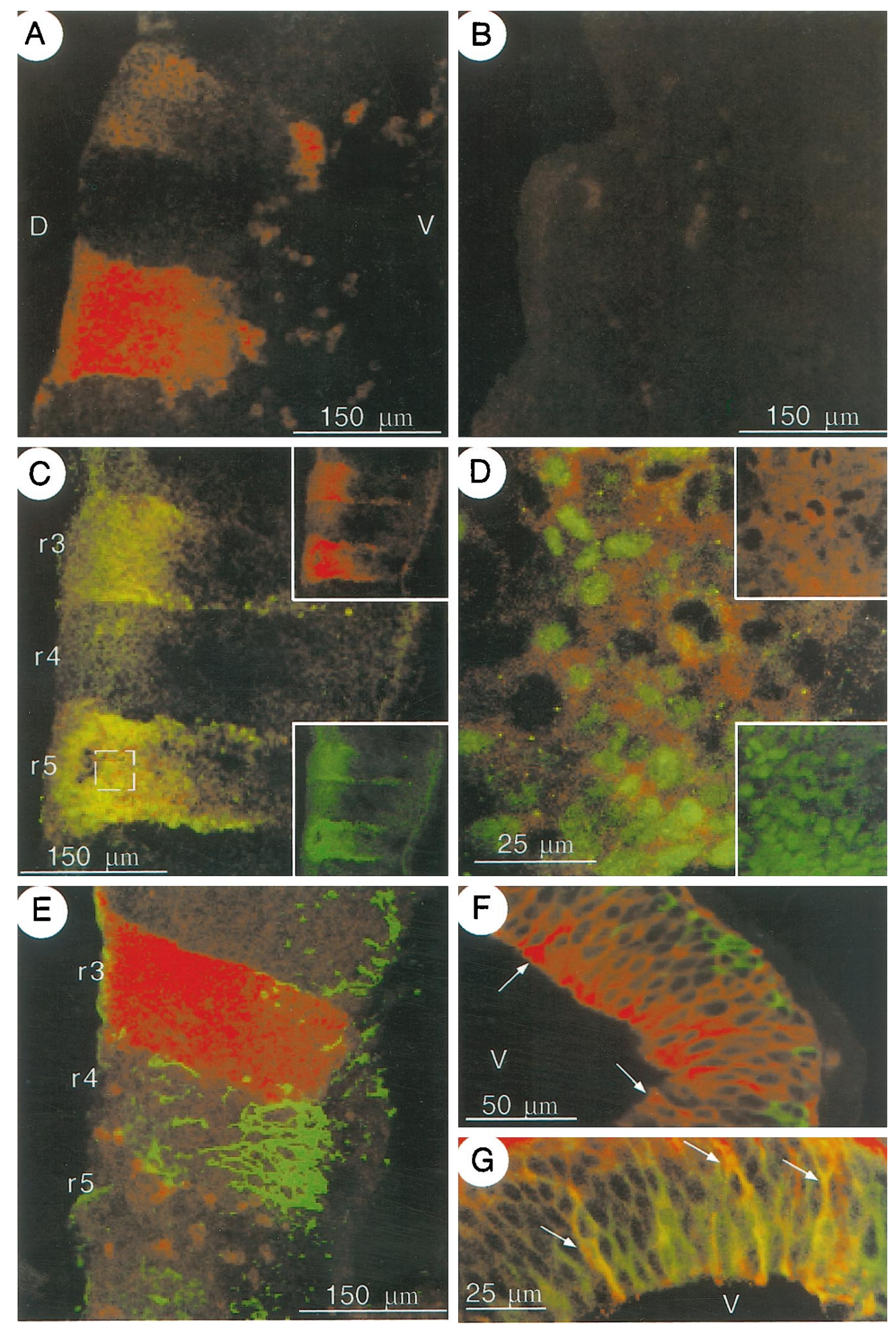

sensory ganglia at E14.5 and glial precursors at E15.5 (Topilko et al., 1994), was used as a marker for glial cells. At both E14.5 and E15.5, we found the Krox-20 staining pattern to be as previously reported and found Kv1.1 and Krox-20 staining patterns overlapped in the small cells adjacent to sensory ganglia (Fig. $6 E$ ) and peripheral nerves (Fig. $6 F-I$ ). Based on their location, morphology, and Krox-20 immunoreactivity, we identify the non-neuronal cells expressing Kv1.1 that are adjacent to sensory ganglia as their glial components (called satellite or boundary cap cells) and those along the pathway of peripheral nerves as Schwann cell precursors.

\section{Trigeminal ganglion and nerve}

At E14.5, the trigeminal ganglion displayed very robust Kv1.1 hybridization signal, with Kv1.1 RNA being detected along the pathways of all three branches of the trigeminal nerve (Fig. 7A). Kv1.1 immunoreactivity was also strong in the trigeminal ganglion and along the trigeminal nerves (Fig. $7 B$ ). There was a 

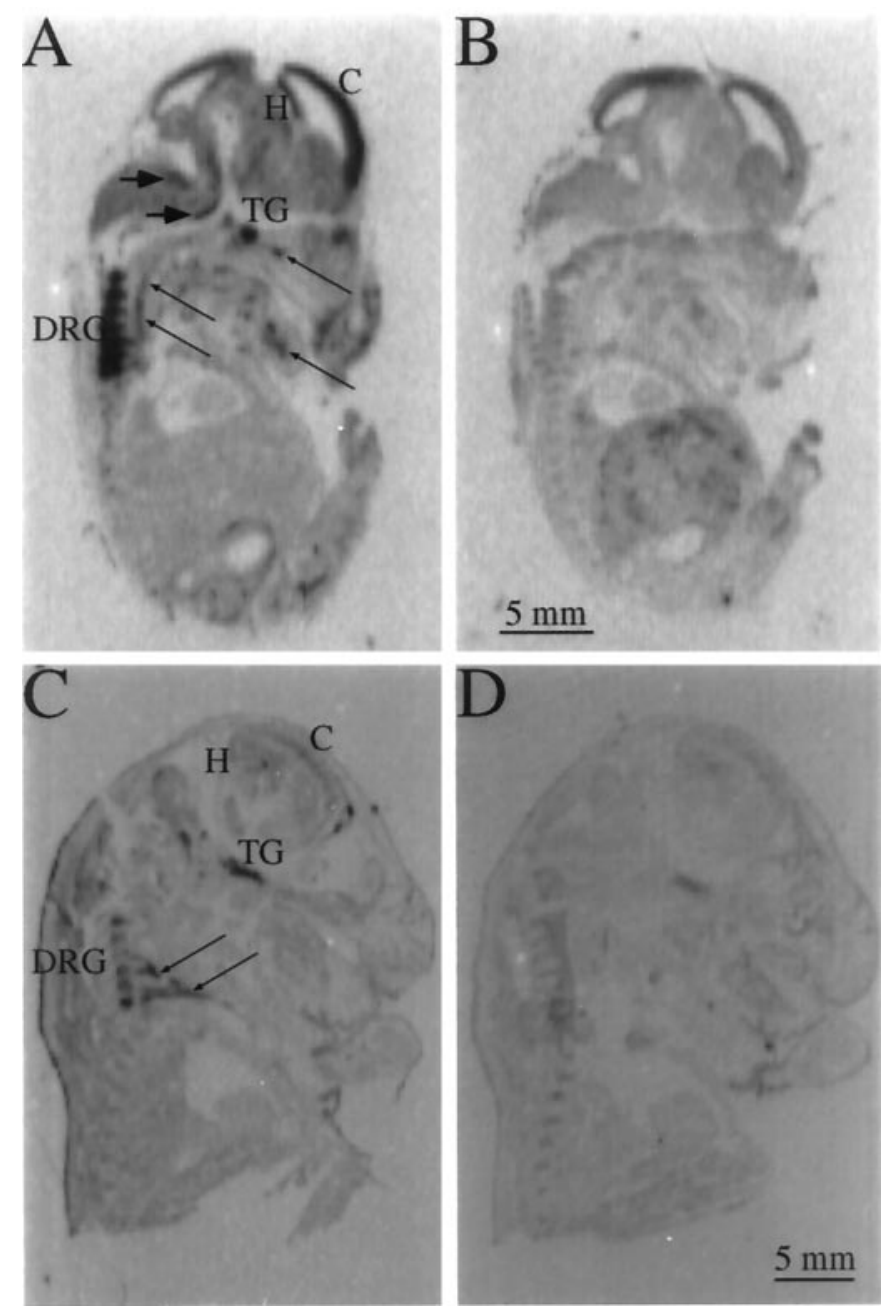

Figure 4. Tissue-specific changes in Kv1.1 expression between E14.5 and E17.5. $A, B$, Autoradiographs of adjacent E14.5 sagittal sections hybridized to ${ }^{33} \mathrm{P}$-labeled $5^{\prime}-\mathrm{Kv} 1.1$ antisense $(A)$ and sense $(B)$ riboprobes to detect Kv1.1-specific signal and background, respectively. Strong Kv1.1 signal is found in both the CNS and PNS, including the cerebral cortex $(C)$, hippocampus $(H)$, trigeminal ganglion $(T G)$, and dorsal root ganglia $(D R G)$, in sensory nuclei of the medulla (large arrows), and along the pathways of peripheral nerves (small, long arrows). $C, D$, E17.5 sagittal sections hybridized to the same $5^{\prime}$-antisense $(C)$ and -sense $(D)$ probes as above, demonstrating much lower Kv1.1 signal density in the cortex $(C)$ and hippocampus $(H)$. The hybridization signal is still strong in sensory ganglia (TG and $D R G$ ) and along the pathways of peripheral nerves (arrows).

substantial overlap in Kv1.1 and TuJ1 staining in the ganglia and nerve fibers as they exit the ganglia (Fig. $7 C-E$ ), but some cells adjacent to the ganglia and those along the pathway of peripheral nerves expressed only Kv1.1 (data not shown; see similar results in DRG). Within the trigeminal ganglion, Kv1.1 was found in neuronal cell bodies of three distinct sizes (Fig. $7 F$ ), again suggesting that Kv1.1 might be localized to multiple neuronal populations in the ganglia. These data indicate that Kv1.1 is present in both the somata and axons of most trigeminal neurons and also in glial cells associated with the axons or ganglia.

Collectively, these data demonstrate that Kv1.1 is expressed in cells with both neuronal and non-neuronal phenotypes at E14.5 and that the non-neuronal cells include multiple populations of glial cells.

\begin{tabular}{|c|c|c|}
\hline & E14.5 & $\mathrm{E} 17.5$ \\
\hline Cerebral cortex & +++ & + \\
\hline Hippocampus & +++ & + \\
\hline Pineal & +++ & + \\
\hline Radial glia & +++ & ++ \\
\hline Superior colliculus & ++ & + \\
\hline Inferior colliculus & ++ & + \\
\hline Epithalamus & ++ & - \\
\hline Pituitary & + & - \\
\hline Cranial ganglia (trigeminal, facial, spiral) & +++ & +++ \\
\hline Dorsal root ganglia & +++ & ++ \\
\hline Thalamus & ++ & $-/+$ \\
\hline Hypothalamus & ++ & - \\
\hline Chief sensory and spinal trigeminal nuclei & ++ & + \\
\hline Medial vestibular nucleus & ++ & + \\
\hline Satellite cells & +++ & +++ \\
\hline Schwann cells/precursors & +++ & +++ \\
\hline Olfactory epithelium & ++ & - \\
\hline Epithelium of the tongue & ++ & - \\
\hline Enteric nervous system & ++ & $? ?$ \\
\hline Thymus & + & - \\
\hline
\end{tabular}

\section{DISCUSSION}

We find that the expression of Kv1.1 undergoes a multiphasic, tissue-specific pattern of regulation during murine development. The same changes in expression were detected using three separate methods: RNase protection, in situ hybridization, and immunocytochemistry. In the embryo, there are two transient peaks of Kv1.1 expression, at E9.5 and E14.5. The first and most tightly regulated expression of Kv1.1 at E9.5 appears to occur primarily in non-neuronal cells. Expression of Kv1.1 does not appear in neuronal cells until the second phase of Kv1.1 expression, which peaks at E14.5. The pattern of murine Kv1.1 expression at E14.5 is strikingly similar to the xKv1.1 pattern detected in stage 42 Xenopus embryos (Ribera and Nguyen, 1993). In both mice and amphibians, Kv1.1 message is found in both the CNS and PNS, where it localizes to areas with significant contributions from neural crest cells, including the trigeminal ganglion, spinal ganglia, and glial cells. Thus, the peak of Kv1.1 expression at E14.5 in mouse may reflect similar developmental events related to neural crest development that are conserved in amphibians and mammals.

The (E14.5) embryonic versus the adult distributions of Kv1.1 can be related in only a subset of the tissues examined here. In peripheral nerves, Kv1.1 is strongly expressed at E14.5, and strong expression continues throughout adult life; however, the punctate pattern of staining seen in the adult (Wang et al., 1993) is not apparent at E14.5. Within the CNS, neurons occupying similar regions express Kv1.1 in both embryos and adults, but because the expression at E14.5 is transient, it is uncertain whether the adult expression occurs in the same cells as in the embryo. In glial cells, Kv1.1 expression is quite different in $14.5 \mathrm{~d}$ embryos and adults. We have demonstrated robust Kv1.1 expression in several embryonic glial populations, whereas in the adult, Kv1.1 is only weakly detected in mature astrocytes (Smart et al., 1997) and mature Schwann cells (Mi et al., 1995). Also, the subcellular localization of Kv1.1 appears to differ in embryonic 


\section{Figure 5}
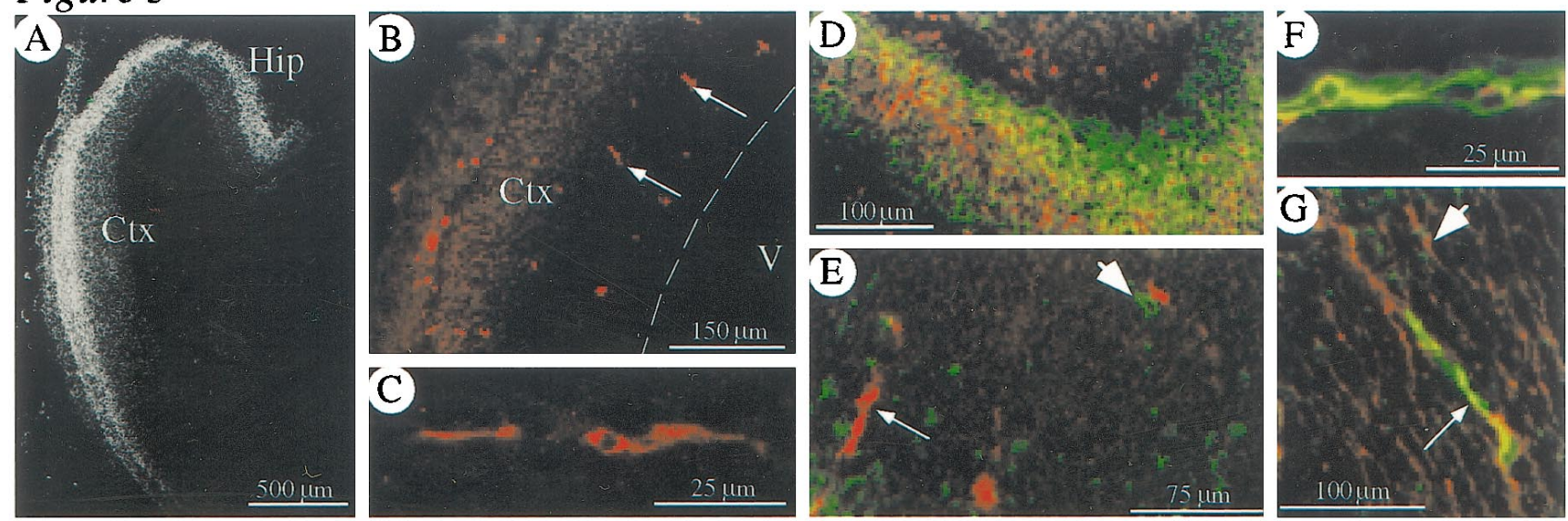

\section{Figure 6}

A)
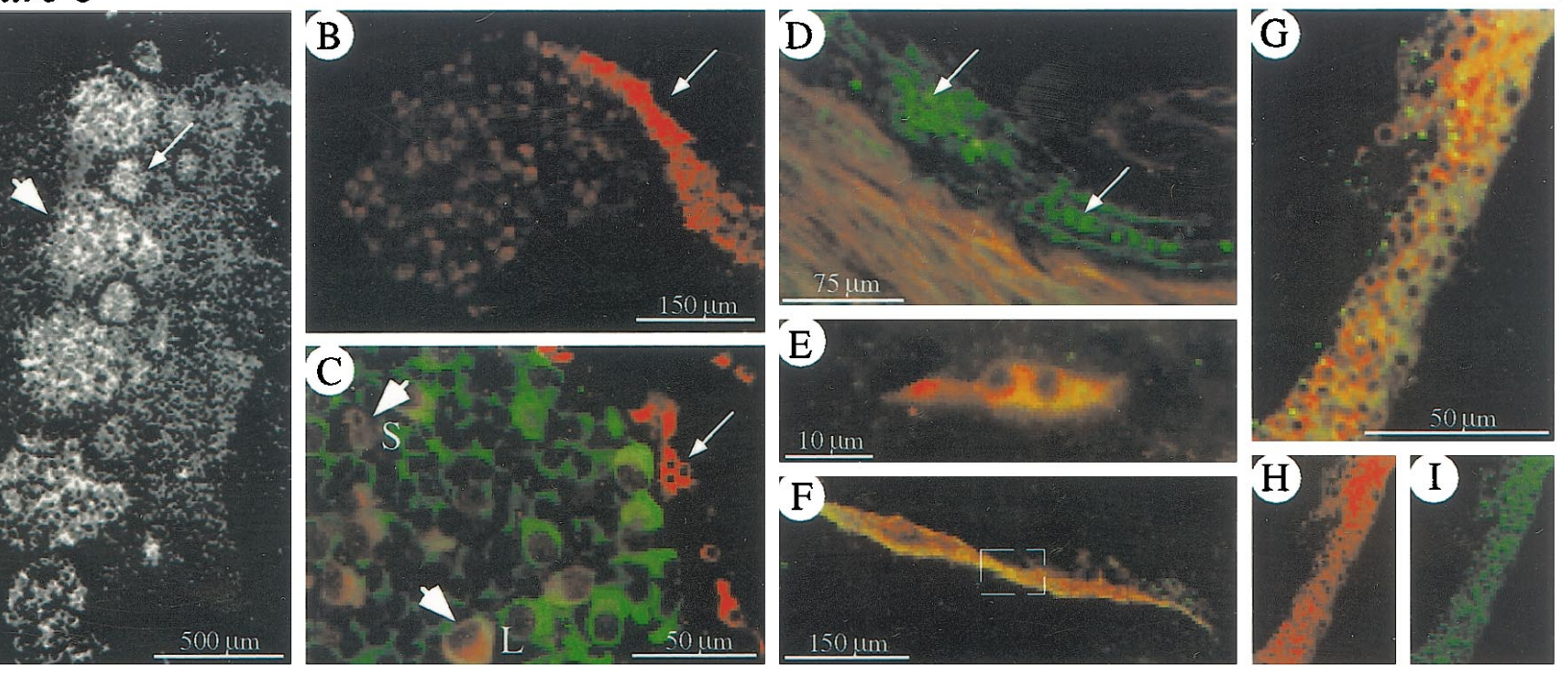

\section{Figure 7}
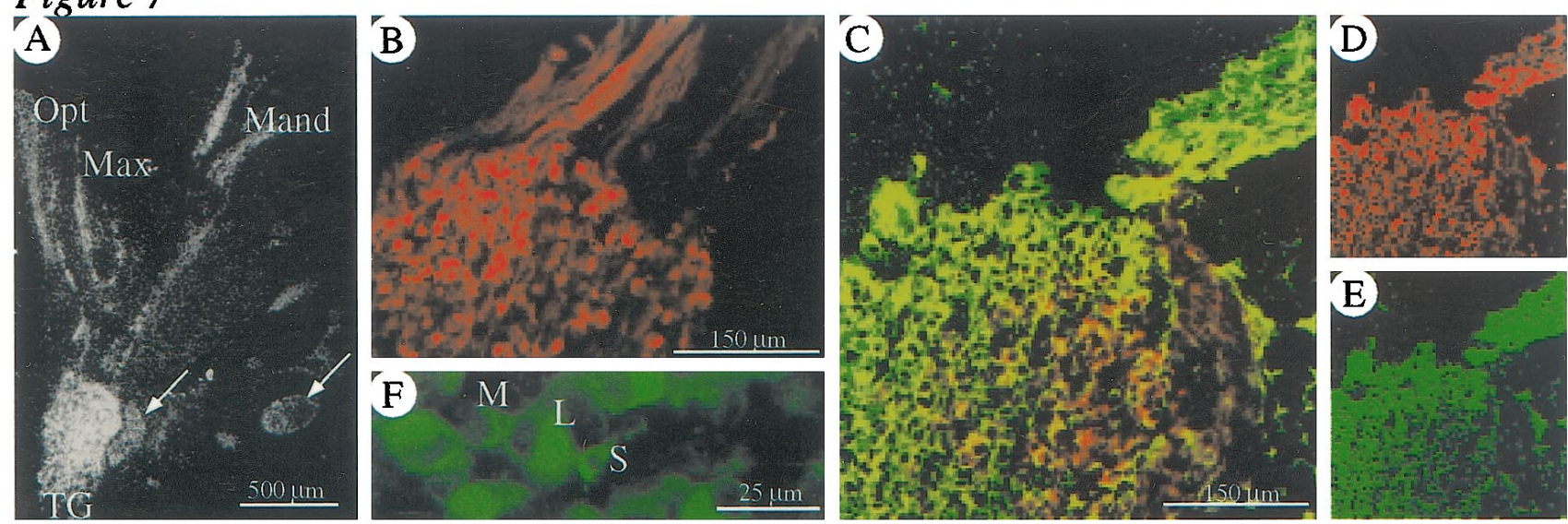

Figure 5. Top. Cellular localization of Kv1.1 in the CNS at E14.5. A, Dark-field image showing strong Kv1.1 hybridization signal in the outer aspects of the cortex (Ctx) and hippocampus (Hip). B, Moderate Kv1.1 immunostaining found in the outer aspect of the Ctx and very robust staining in large cells found in the subventricular zone (arrows). The ventricle $(V)$ is to the right, and the ventricular edge is marked with a dashed line. $C$, Magnification of a single large cell positive for Kv1.1 in the subventricular zone of the cortex. $D$, Colabeling ICC in the hippocampus demonstrating some overlap in Kv1.1 (red) and TuJ1 (green) localization in the differentiating field. E, Double-staining ICC in the cortex (cortical plate toward the bottom left and ventricle toward the top right) showing that Kv1.1 (red, small arrow) and TuJ1 (green) proteins are not localized in the same cells in the subventricular zone. A single TuJ1-positive cell (large arrowhead) is seen immediately adjacent to a cell with Kv1.1 staining. F, Colabeling ICC with anti-Kv1.1 (red) and anti-vimentin (green) demonstrating colocalization in large cells in the subventricular zone of the pons. $G$, Double immunostaining showing that Kv1.1 immunoreactivity (green) overlaps with that of RC-2 (red) in some cells in the subventricular zone of the cortex (small arrow). Some cells are positive for RC-2 only (large arrowhead). The ventricle is toward the lower right. 
and in mature Schwann cells, with strong, diffuse expression in the embryo versus an exclusively perinuclear localization in mature Schwann cells. Thus, although the cellular patterns of Kv1.1 expression can be correlated between embryo and adult, the level of expression and subcellular localization usually differ.

Postnatally, expression of Kv1.1 in the CNS is low at birth (P0) and rises dramatically at the end of the second postnatal week (P12-P15). This postnatal upregulation immediately precedes the onset of a seizure phenotype in Kv1.1-null mice (Smart et al., 1998), suggesting that the seizure phenotype in Kv1.1-null mutants is attributable at least in part to functional deficiencies in mature neurons.

Our results show that dramatic changes in Kv1.1 RNA and protein levels can occur over $24 \mathrm{hr}$, suggesting that both Kv1.1 message and protein are labile and turnover is tightly regulated. In addition, we found that the tissues with the highest Kv1.1 transcript levels also exhibit the strongest Kv1.1 immunoreactivity. This is consistent with the findings of others that the development of $I_{\mathrm{Kv}}$ in Xenopus neurons requires a period of new RNA synthesis (Ribera and Spitzer, 1989) and coincides with increasing xKv1.1 transcript levels (Gurantz et al., 1996).

\section{Potential functions of Kv1.1 during development}

In mature neurons, the functions of voltage-gated $\mathrm{K}^{+}$currents have been studied extensively. Delayed rectifier currents (to which Kv1.1 is thought to contribute) repolarize axons after action potentials and in this way are thought to regulate neuronal excitability (Hille, 1992). Although our studies do not directly assess the developmental roles of Kv1.1, several factors suggest this channel may serve different functions in embryos than it does in mature neurons. First, Kv1.1 is expressed at very early stages of nervous system development, before the extension of neurites or the establishment of synaptic connections in many cells expressing Kv1.1. Second, Kv1.1 is strongly expressed in non-neuronal (including glial) cells in the embryo. Finally, the tightly regulated, transient expression of Kv1.1 in embryos suggests this channel is involved in developmental processes that occur only at specific times in embryogenesis.

By what mechanism(s) might a Kv channel influence cellular processes involved in development? The simplest explanation is that, by influencing resting membrane potential or repolarization rates, Kv1.1 regulates calcium influx, thereby affecting calciumsensitive processes such as protein phosphorylation, changes in gene expression, and release of intercellular signaling molecules. Several developmental processes are known to be influenced by the amount or rate of calcium influx into cells, including neuronal cell migration (Rakic and Komuro, 1995; Goldman, 1996; Komuro and Rakic, 1996), growth cone migration (Cohan et al., 1987; Neely and Gesemann, 1994; Williams and Cohan, 1995), Schwann cell migration (Letourneau et al., 1991; Anton et al., 1995), cell-cell adhesion (for review, see Damsky et al., 1993; Marrs and Nelson, 1996), and neuronal differentiation (for review, see Moody et al., 1991; Emerit et al., 1992; Finkbeiner and Greenberg, 1996). Although calcium-dependent mechanisms are well established, it is possible that Kv1.1 expression may affect transduction of other developmental signals or may be involved in direct cell-cell recognition.

\section{Possible cellular processes regulated by Kv1.1}

When one considers the tissue- or cell-specific localization of Kv1.1, the timing of its expression, and our current knowledge of the cellular processes taking place in tissues or cells expressing Kv1.1 during development, there is evidence to support roles for Kv1.1 in at least three distinct cellular processes: cell-cell adhesion, migration, and proliferation.

Kv1.1 might play a role in cell-cell adhesion in the rhombomeres, which are periodic bulges in developing vertebrate hindbrains that underlie the segmental patterning of the hindbrain and delineate molecular compartments of restricted gene expression (for review, see Nieto et al., 1992). Pairs of rhombomeres give rise to associated sensory ganglia, brachiomotor nerves, and other neural crest derivatives such as glia, bone, cartilage, and pigment epithelium (for review, see Lumsden and Keynes, 1989). For example, rhombomeres 2 and 3 give rise to the trigeminal ganglion, motor roots of the trigeminal nerve, and associated glial components, whereas rhombomeres 4 and 5 give rise to the facial/vestibular ganglion, its motor roots, and glia. In chick embryos, clonal analysis indicates that only a minor degree of cellular mixing occurs between rhombomeres (Fraser et al., 1990), and rhombomeres also exhibit differential adhesiveness that is cadherin-mediated (Guthrie et al., 1993; Wizenmann and Lumsden, 1997), suggesting there may be differential expression or regulation of cell adhesion molecules in alternating rhombomeres. Cadherins are a large family of calcium-dependent adhesions molecules that mediate homophilic interactions between cells (for review, see Grunwald, 1993), and their adhesive

\section{$\leftarrow$}

Figure 6. Middle. Cellular localization of Kv1.1 in dorsal root ganglia and peripheral nerves at E14.5 and E15.5. $A-D$ are from E14.5 embryos, and E-I are from E15.5 embryos. $A$, Dark-field image showing a strong Kv1.1 hybridization signal in a subset of cells in the dorsal root ganglia (large arrowhead). Kv1.1 signal is also detected in nearby bone and cartilage (small arrow), but it is unlikely this signal is specific for Kv1.1, because it did not develop in all experiments and a strong background signal developed in bone using the control probe in a portion of experiments. $B$, ICC detecting strong Kv1.1 staining in some cells of the dorsal root ganglia and very robust immunoreactivity in cells along the emerging nerve fibers (arrow). $C$, Colabeling ICC with anti-Kv1.1 (red) and TuJ1 (green) showing localization of both proteins in two sizes of neurons [small $(S)$ and large $(L)$ ] in the ganglia (large arrowheads), with only Kv1.1 immunoreactivity seen in the small cells adjacent to the ganglion (small arrow). D, Double immunolabeling with anti-Kv1.1 ( green) and anti-GAP-43 (red), an axonal marker, showing both proteins in peripheral axons and only Kv1.1 staining in small cells adjacent to the axons (arrows). E, Double immunostaining with Kv1.1 (red) and Krox-20 (green) demonstrating localization of both proteins in the small, rounded cells adjacent to sensory ganglia. $F-I$, Colabeling ICC with anti-Kv1.1 (red) and anti-Krox-20 ( green) at E15.5 demonstrating colocalization of both proteins in small cells adjacent to a peripheral nerve. $F$ is a low-magnification image showing a large section of nerve. $G$ is an approximately fivefold magnification of the boxed area in $F$.

Figure 7. Bottom. Cellular localization of Kv1.1 in the trigeminal ganglion and nerve at E14.5. A, Dark-field image exhibiting strong Kv1.1 hybridization signal in cell bodies of the trigeminal ganglion $(T G)$ and along the pathways of all three branches of the trigeminal nerve or the ophthalmic $(O p t)$, maxillary (Max), and mandibular (Mand) nerves. Signal was also detected in nearby bone and cartilage (small arrows) but is probably not a specific signal (see Fig. 6A). B, Robust Kv1.1 immunostaining in the trigeminal ganglion and along emerging nerve fibers. $C$ - $E$, Double-immunofluorescent staining with anti-Kv1.1 (red) and the early neuronal marker TuJ1 (green) demonstrating substantial, but not complete, colocalization of both proteins in cell bodies in the trigeminal ganglion and in emerging axons. $F$, Kv1.1 immunoreactivity in three different sizes of neuronal cell bodies in the trigeminal ganglion [intermediate $(M)$, large $(L)$, and small $(S)$ ]. 
function appears to be regulated by reversible phosphorylation of cadherin-associated molecules that may involve protein kinase $\mathrm{C}$ (for review, see Nagafuchi et al., 1993). At least one member of this family, cadherin 6 , has been found to be expressed in a rhombomere-restricted pattern at E9.5 (Inoue et al., 1997). Our finding that Kv1.1 is broadly expressed in rhombomeres 3 and 5 at E9.5 suggests that Kv1.1 might influence cell-cell adhesion within these rhombomeres, perhaps by regulating the calciumsensitive phosphorylation of cytoplasmic molecules that interact with cadherins.

Several lines of evidence suggest Kv1.1 might play a role in migration. First, Kv1.1 is expressed in several cell types that are migratory or involved in migration. At both E9.5 and E14.5, Kv1.1 is strongly expressed in radial glia, which provide the scaffolding for migration of proliferating progenitors and newly differentiated neurons in the developing CNS (for review, see Jacobson, 1991). At E14.5, Kv1.1 is found in the axons of peripheral nerves and in Schwann cell precursors, which migrate into the periphery along these axons (for review, see Jacobson, 1991). Second, migrations of neurons, glia, and growth cones have all been shown to be regulated by calcium influx, which we have suggested could be regulated by $\mathrm{Kv}$ channel expression. Interestingly, the cadherin family of adhesion molecules has also been shown to be involved in the migration of growth cones (Letourneau et al., 1990) and Schwann cells (Letourneau et al., 1991) to their peripheral targets, suggesting Kv1.1 might influence migration by regulating the calcium-sensitive phosphorylation of molecules that interact with these cell adhesion molecules. Finally, weaver mutant mice, which have a deficit in the movement of a subset of cerebellar neurons to their adult locations (Hatten et al., 1986; Maricich et al., 1997), have a mutation in another $\mathrm{K}^{+}$channel, the G-protein-coupled inward rectifier GIRK2 (Patil et al., 1995). Although the mechanism responsible for the migratory deficit is not understood, these findings indicate the GIRK2 is required for the normal migration of these neurons and are consistent with the idea that other $\mathrm{K}^{+}$ channels might also be involved in neuronal migration.

There is substantial evidence suggesting Kv1.1 plays a role in Schwann cell proliferation. First, cultured postnatal Schwann cells express a delayed rectifier current, increases in current density parallel proliferation in the Schwann cells, and blockade of $I_{\mathrm{Kv}}$ inhibits their proliferation (Wilson and Chiu, 1993). Second, Kv1.1 is expressed in proliferating cultured Schwann cells, and its expression and $I_{\mathrm{Kv}}$ current density are downregulated as cells stop proliferating and begin differentiating (Chiu and Wilson, 1989; Chiu et al., 1994). Third, in the dysmyelinating mouse mutant shiverer, there is an approximately twofold increase in the number of CNS glia, as well as an approximately fourfold increase in Kv1.1 expression in individual glial cells (Wang et al., 1995). Fourth, C6 glioma cells, a cultured cell line that is often used to study glial differentiation, express Kv1.1 (Wang et al., 1992). Strong Kv1.1 expression seems to be the major determinant of the resting membrane potential in undifferentiated C6 glioma cells, and pharmacological treatments that inhibit proliferation also induce a decrease in Kv1.1 RNA levels (Allen et al., 1998). Our finding that Kv1.1 is strongly expressed in glia and glial precursors during development is consistent with a potential role for this channel in glial proliferation in vivo.

Thus, there are multiple developmental processes in which Kv1.1 might be involved. Our results suggest that the expression of Kv1.1 in multiple populations of embryonic cells may provide a means for differential regulation of these processes in different populations within the developing mammalian nervous system.

\section{REFERENCES}

Allen M, Koh D-S, Tempel BL (1998) Cyclic AMP regulates potassium channel expression in C6 glioma cells by destabilizing Kv1.1 mRNA. Proc Natl Acad Sci USA, in press.

Alvarez-Buylla A, Buskirk DR, Nottebohm F (1987) Monoclonal antibody reveals radial glia in adult avian brain. J Comp Neurol 264:159-170.

Anton ES, Hadjiargyrou M, Patterson PH, Matthew WD (1995) CD9 plays a role in Schwann cell migration in vitro. J Neurosci 15:584-595.

Ausubel FM (1992) Current protocols in molecular biology. New York: Wiley.

Barish ME (1986) Differentiation of voltage-gated potassium current and modulation of excitability in cultured amphibian spinal neurones. J Physiol (Lond) 375:229-250.

Bosma MM, Allen ML, Martin TM, Tempel BL (1993) PKA-dependent regulation of mKv1.1, a mouse Shaker-like potassium channel gene, when stably expressed in CHO cells. J Neurosci 13:5242-5250.

Burger C, Ribera AB (1996) Xenopus spinal neurons express Kv2 potassium channel transcripts during embryonic development. J Neurosci 16:1412-1421.

Carr PA, Nagy JI (1993) Emerging relationships between cytochemical properties and sensory modality transmission in primary sensory neurons. Brain Res Bull 30:209-219.

Chiu SY, Wilson GF (1989) The role of potassium channels in Schwann cell proliferation in Wallerian degeneration of explant rabbit sciatic nerves. J Physiol (Lond) 408:199-222.

Chiu SY, Scherer SS, Blonski M, Kang SS, Messing A (1994) Axons regulate the expression of Shaker-like potassium channel genes in Schwann cells in peripheral nerve. Glia 12:1-11.

Chomczynski P, Sacchi N (1987) Single-step method of RNA isolation by acid guanidinium thiocyanate-phenol-chloroform extraction. Anal Biochem 162:156-159.

Cohan CS, Connor JA, Kater SB (1987) Electrically and chemically mediated increases in intracellular calcium in neuronal growth cones. J Neurosci 7:3588-3599.

Damsky C, Sutherland A, Fisher S (1993) Extracellular matrix 5: adhesive interactions in early mammalian embryogenesis, implantation, and placentation. FASEB J 7:1320-1329.

deLatt SW, Bluemink JG (1974) New membrane formation during cytokinesis in normal and cytochalasin B-treated eggs of Xenopus laevis. J Cell Biol 60:529-540.

Desarmenien MG, Clendening B, Spitzer NC (1993) In vivo development of voltage-dependent ionic currents in embryonic Xenopus spinal neurons. J Neurosci 13:2575-2581.

Easter Jr SS, Ross LS, Frankfurter A (1993) Initial tract formation in the mouse brain. J Neurosci 13:285-299.

Emerit MB, Riad M, Hamon M (1992) Trophic effects of neurotransmitters during brain maturation. Biol Neonate 62:193-201.

Finkbeiner S, Greenberg ME (1996) Ca(2+)-dependent routes to Ras: mechanisms for neuronal survival, differentiation, and plasticity? Neuron 16:233-236.

Fraser S, Keynes R, Lumsden A (1990) Segmentation in the chick embryo hindbrain is defined by cell lineage restrictions. Nature 344:431-435.

Goddard JM, Rossel M, Manley NR, Capecchi MR (1996) Mice with targeted disruption of Hoxb-1 fail to form the motor nucleus of the VIIth nerve. Development 122:3217-3228.

Goldman SA, Williams S, Barami K, Lemmon V, Nedergaard M (1996) Transient coupling of $\mathrm{Ng}$-CAM expression to $\mathrm{Ng}$-CAM-dependent calcium signaling during migration of new neurons in the adult songbird brain. Mol Cell Neurosci 7:29-45.

Goslin K, Schreyer DJ, Skene JH, Banker G (1990) Changes in the distribution of GAP-43 during the development of neuronal polarity. J Neurosci 10:588-602.

Grunwald GB (1993) The structural and functional analysis of cadherin calcium-dependent cell adhesion molecules. Curr Opin Cell Biol 5:797-805.

Gurantz D, Ribera AB, Spitzer NC (1996) Temporal regulation of Shaker- and Shab-like potassium channel gene expression in single embryonic spinal neurons during $\mathrm{K}^{+}$current development. J Neurosci 16:3287-3295.

Guthrie S, Prince V, Lumsden A (1993) Selective dispersal of avian rhombomere cells in orthotopic and heterotopic grafts. Development 118:527-538.

Hagiwara S, Miyasaki S-I, Moody WJ, Patlak J (1975) Voltage clamp 
analysis of two inward current mechanisms in the egg cell membrane of a starfish. J Gen Physiol 65:617-644.

Hatten ME, Liem RK, Mason CA (1986) Weaver mouse cerebellar granule neurons fail to migrate on wild-type astroglial processes in vitro. J Neurosci 6:2676-2683.

Hille B (1992) Potassium channels and chloride channels. In: Ionic channels of excitable membranes, pp 115-139. Sunderland, MA: Sinauer.

Inoue T, Chisaka O, Matsunami H, Takeichi M (1997) Cadherin-6 expression transiently delineates specific rhombomeres, other neural tube subdivisions, and neural crest subpopulations in mouse embryos. Dev Biol 183:183-194.

Jacobson M (1991) Developmental neurobiology. New York: Plenum.

Jones SM, Ribera AB (1994) Overexpression of a potassium channel gene perturbs neural differentiation. J Neurosci 14:2789-2799.

Kai K-MA (1989) Cytochemistry of the trigeminal and dorsal root ganglia and spinal cord of the rat. Comp Biochem Physiol 93:183-193.

Komuro H, Rakic P (1996) Intracellular Ca2+ fluctuations modulate the rate of neuronal migration. Neuron 17:275-285.

Letourneau PC, Shattuck TA, Roche FK, Takeichi M, Lemmon V (1990) Nerve growth cone migration onto Schwann cells involves the calcium-dependent adhesion molecule, $N$-cadherin. Dev Biol 138:430-442.

Letourneau PC, Roche FK, Shattuck TA, Lemmon V, Takeichi M (1991) Interactions of Schwann cells with neurites and with other Schwann cells involve the calcium-dependent adhesion molecule, $N$-cadherin. J Neurobiol 22:707-720.

Lockery SR, Spitzer NC (1992) Reconstruction of action potential development from whole-cell currents of differentiating spinal neurons. J Neurosci 12:2268-2287.

Lumsden A, Keynes R (1989) Segmental patterns of neuronal development in the chick hindbrain. Nature 337:424-428.

Maricich SM, Soha J, Trenkner E, Herrup K (1997) Failed cell migration and death of Purkinje cells and deep nuclear neurons in the weaver cerebellum. J Neurosci 17:3675-3683.

Marrs JA, Nelson WJ (1996) Cadherin cell adhesion molecules in differentiation and embryogenesis. Int Rev Cytol 165:159-205.

Mi H, Deerinck TJ, Ellisman MH, Schwarz TL (1995) Differential distribution of closely related potassium channels in rat Schwann cells. J Neurosci 15:3761-3774.

Misson JP, Edwards MA, Yamamoto M, Caviness Jr VS (1988) Identification of radial glial cells within the developing murine central nervous system: studies based upon a new immunohistochemical marker. Brain Res 44:95-108.

Moody SA, Quigg MS, Frankfurter A (1989) Development of the peripheral trigeminal system in the chick revealed by an isotype-specific anti-beta-tubulin monoclonal antibody. J Comp Neurol 279:567-580.

Moody WJ (1985) The development of calcium and potassium currents during oogenesis in the starfish, Leptasterias hexactis. Dev Biol 112:405-413.

Moody WJ, Simoncini L, Coombs JL, Spruce AE, Villaz M (1991) Development of ion channels in early embryos. $\mathrm{J}$ Neurobiol 22:674-684.

Naciff JM, Behbehani MM, Kaetzel MA, Dedman JR (1996) Annexin VI modulates $\mathrm{Ca}^{2+}$ and $\mathrm{K}^{+}$conductances of spinal cord and dorsal root ganglion neurons. Am J Physiol 271:C2004-C2015.

Nagafuchi A, Tsukita S, Takeichi M (1993) Transmembrane control of cadherin-mediated cell-cell adhesion. Semin Cell Biol 4:175-181.

Neely MD, Gesemann M (1994) Disruption of microfilaments in growth cones following depolarization and calcium influx. $\mathrm{J}$ Neurosci 14:7511-7520.

Nieto MA, Bradley LC, Hunt P, Das G-R, Krumlauf R, Wilkinson DG (1992) Molecular mechanisms of pattern formation in the vertebrate hindbrain. Ciba Found Symp 165:92-102; discussion, 102-107.

O'Dowd DK, Ribera AB, Spitzer NC (1988) Development of voltagedependent calcium, sodium, and potassium currents in Xenopus spinal neurons. J Neurosci 8:792-805.
Patil N, Cox DR, Bhat D, Faham M, Myers RM, Peterson AS (1995) A potassium channel mutation in weaver mice implicates membrane excitability in granule cell differentiation. Nat Genet 11:126-129.

Rakic P, Komuro H (1995) The role of receptor/channel activity in neuronal cell migration. J Neurobiol 26:299-315.

Ribera AB (1996) Homogeneous development of electrical excitability via heterogeneous ion channel expression. J Neurosci 16:1123-1130.

Ribera AB, Nguyen DA (1993) Primary sensory neurons express a Shaker-like potassium channel gene. J Neurosci 13:4988-4996.

Ribera AB, Spitzer NC (1989) A critical period of transcription required for differentiation of the action potential of spinal neurons. Neuron 2:1055-1062.

Ribera AB, Spitzer NC (1991) Differentiation of delayed rectifier potassium current in embryonic amphibian myocytes. Dev Biol 144:119-128.

Rizzo MA, Nonner W (1992) Transient K current in the somatic membrane of cultured central neurons of embryonic rat. J Neurophysiol 68:1708-1719.

Simoncini L, Block ML, Moody WJ (1988) Lineage-specific development of calcium currents during embryogenesis. Science 242:1572-1575.

Smart SL, Bosma MM, Tempel BL (1997) Identification of the delayed rectifier potassium channel, Kv1.6, in cultured astrocytes. Glia 20:127-134.

Smart SL, Lopantsev V, Zhang CL, Robbins CA, Wang H, Chiu SY, Schwartzkroin PA, Messing A, Tempel BL (1998) Deletion of the Kv1.1 potassium channel causes epilepsy in mice. Neuron 20:1-20.

Spruce AE, Moody WJ (1992) Developmental sequence of expression of voltage-dependent currents in embryonic Xenopus laevis myocytes. Dev Biol 154:11-22.

Surmeier DJ, Stefani A, Foehring RC, Kitai ST (1991) Developmental regulation of a slowly-inactivating potassium conductance in rat neostriatal neurons. Neurosci Lett 122:41-46.

Topilko P, Schneider M-S, Levi G, Baron V-E-A, Chennoufi AB, Seitanidou T, Babinet C, Charnay P (1994) Krox-20 controls myelination in the peripheral nervous system. Nature 371:796-799.

Wang H, Kunkel DD, Martin TM, Schwartzkroin PA, Tempel BL (1993) Heteromultimeric $\mathrm{K}^{+}$channels in terminal and juxtaparanodal regions of neurons. Nature 365:75-79.

Wang H, Kunkel DD, Schwartzkroin PA, Tempel BL (1994) Localization of Kv1.1 and Kv1.2, two K channel proteins, to synaptic terminals, somata, and dendrites in the mouse brain. J Neurosci 14:4588-4599.

Wang H, Allen ML, Grigg JJ, Noebels JL, Tempel BL (1995) Hypomyelination alters $\mathrm{K}^{+}$channel expression in mouse mutants shiverer and Trembler. Neuron 15:1337-1347.

Wang SY, Castle NA, Wang GK (1992) Identification of RBK1 potassium channels in C6 astrocytoma cells. Glia 5:146-153.

Wilkinson DG, Bhatt S, Chavrier P, Bravo R, Charnay P (1989) Segment-specific expression of a zinc-finger gene in the developing nervous system of the mouse. Nature 337:461-464.

Williams DK, Cohan CS (1995) Calcium transients in growth cones and axons of cultured Helisoma neurons in response to conditioning factors. J Neurobiol 27:60-75.

Wilson GF, Chiu SY (1993) Mitogenic factors regulate ion channels in Schwann cells cultured from newborn rat sciatic nerve. J Physiol (Lond) 470:501-520.

Wizenmann A, Lumsden A (1997) Segregation of rhombomeres by differential chemoaffinity. Mol Cell Neurosci 9:448-459.

Wu RL, Barish ME (1994) Astroglial modulation of transient potassium current development in cultured mouse hippocampal neurons. J Neurosci 14:1677-1687.

Zona C, Eusebi F, Miledi R (1990) Glycosylation is required for maintenance of functional voltage-activated channels in growing neocortical neurons of the rat. Proc R Soc Lond [Biol] 239:119-127. 